\title{
Diagnostic accuracy of multi-slice computed tomography in children with Abernethy malformation
}

\author{
Chen Guo ${ }^{\dagger}$, Yu-Min Zhong ${ }^{*}$ (D), Qian Wang ${ }^{\dagger}$, Li-Wei Hu, Xiao-Hong Gu, Hong Shao, Wei Wu, Jian-Feng Cao and
} Hai-Sheng Qiu

\begin{abstract}
Background: Abernethy malformation is a rare congenital abnormality. Imaging examination is an important method for the diagnosis. The purpose of this study was to demonstrate manifestations of multi-slice computed tomography (MSCT) in Abernethy malformation and its diagnostic accuracy.

Methods: Fourteen children with Abernethy malformation were admitted to our center in China between July 2011 and January 2018. All 14 patients (eight males and six females) received MSCT and digital subtraction angiography (DSA) while eight patients also received ultrasound. The patients' age ranged from 1 to 14 (median age 8 years old). The clinical records of the patients were retrospectively reviewed. MSCT raw data were transferred to an Advantage Windows 4.2 or 4.6 workstation (General Electric Medical Systems, Waukesha, WI). We compared the findings of MSCT with DSA and surgical results in order to ascertain diagnostic accuracy.

Results: Three cases had type Ib Abernethy malformation and eleven cases had type II. Two cases of type II Abernethy malformation were misdiagnosed as type lb using MSCT. Comparing the findings of MSCT with DSA and surgical results, the accuracy of MSCT was $85.7 \%(12 / 14)$, in which $100.0 \%(3 / 3)$ were type lb and $81.8 \%(9 / 11)$ were type II. Clinical information included congenital heart disease, pulmonary hypertension, diffuse pulmonary arteriovenous fistula, abnormal liver function, hepatic nodules, elevated blood ammonia, and hepatic encephalopathy. Eleven cases were treated after diagnosis. One patient with Abernethy malformation type Ib (1/3) underwent liver transplantation. Seven patients with Abernethy malformation type II (7/11) were treated by shunt occlusion, received laparoscopy, or were treated with open surgical ligation. Another three patients (3/11) with Abernethy malformation type II were treated by interventional portocaval shunt occlusion under DSA.

Conclusion: MSCT attains excellent capability in diagnosing type II Abernethy malformation and further shows the location of the portocaval shunt. DSA can help when it is hard to determine diagnosis between Abernethy type lb and II using MSCT.
\end{abstract}

Keywords: Abernethy malformation, Angiography, Tomography

\footnotetext{
* Correspondence: zyumin2002@163.com

${ }^{\dagger}$ Chen Guo and Qian Wang contributed equally to this work.

Diagnostic Imaging Center, Shanghai Children's Medical Center affiliated with Shanghai Jiao Tong University School of Medicine, 1678 Dong Fang Road, Shanghai 200127, People's Republic of China
}

(c) The Author(s). 2019 Open Access This article is distributed under the terms of the Creative Commons Attribution 4.0 International License (http://creativecommons.org/licenses/by/4.0/), which permits unrestricted use, distribution, and reproduction in any medium, provided you give appropriate credit to the original author(s) and the source, provide a link to the Creative Commons license, and indicate if changes were made. The Creative Commons Public Domain Dedication waiver (http://creativecommons.org/publicdomain/zero/1.0/) applies to the data made available in this article, unless otherwise stated. 


\section{Background}

Abernethy malformation is a rare congenital abnormality that was described by John Abernethy in 1793. It is characterized by a congenital extrahepatic portosystemic shunt between the portal vein and systemic circulation. It was defined by Morgan et al. [1] in 1994 as type Ia, type Ib, and type II, based on whether the liver is perfused with portal blood, and whether the superior mesenteric vein and splenic vein join to form a confluence in the portal vein. A variety of clinical presentations can be evidenced in those with Abernethy malformation. It is very difficult to diagnose solely on the basis of clinical manifestations. Imaging examination is an important method for the diagnosis of Abernethy malformation. Conventional cine angiography, which is considered a gold standard, requires catheterization with ionizing radiation. Recent developments in CT technology with better spatial and temporal resolution have increased its clinical use in children. The source images can be reformatted in any desired plane for better visualization of the vascular anatomy. The aim of this study was to demonstrate manifestations of MSCT in Abernethy malformation and to evaluate its diagnostic accuracy.

\section{Types of Abernethy malformation}

There are two types of Abernethy Malformation (Fig. 1). Type I is defined as a complete porto- systemic shunt, in which the portal vein merges with the inferior vena cava (IVC) in an end-to-end shunt. In this situation, the liver is not perfused with portal blood. Type I is further subclassified into types Ia and Ib according to whether superior mesenteric vein and splenic vein join to form a confluence with the portal vein or not. Abernethy Malformation type II refers to a partial shunt, consisting of a side-to-side connection between the portal vein and the systemic venous circulation, with partial portal blood flow to the liver.

\section{Methods}

\section{Patients}

The ethics commission of our hospital approved this retrospective study. Fourteen pediatric cases of Abernethy malformation were admitted to our hospital between July 2011 and January 2018. All 14 patients (eight males and six females) received MSCT and DSA (digital subtraction angiography). The age of all patients ranged from 1 to 14 years, with a median age of 8 years. The clinical records of the patients were reviewed. All patients underwent DSA under anesthesia. For MSCT examination, five patients younger than 6 years of age were sedated with orally administered chloral hydrate or/and intramuscular phenobarbital.

\section{CT scanning protocols}

MSCT angiography was performed on a 16-row CT scanner (Lightspeed 16, General Electric Medical Systems, Milwaukee, WI, USA)(case 1-11) or a 64-slice high definition CT scanner (Discovery CT 750 HD, General Electric Medical Systems, Waukesha, WI, USA)(case 12-14). The parameters for CT using the 64-slice CT scanner were as follows: a low-dose CT protocol (100-120 kVp, $50 \mathrm{~mA}$ ) and the following parameters: collimation $16 \times 1.25 \mathrm{~mm}$, pitch $1.375: 1$, table feed $13.75 \mathrm{~mm} /$ rotation, slice thickness $0.625 \mathrm{~mm}$ or $1.25 \mathrm{~mm}$. The parameters for CT using 16-slice CT scanner were as follows: $120 \mathrm{kV}, 100 \mathrm{~mA}$, pitch 1.375:1, table feed $13.75 \mathrm{~mm} /$ rotation, slice thickness $0.625 \mathrm{~mm}$. Nonionic contrast agent $(2 \mathrm{ml} / \mathrm{kg})$ was injected throughout the scan via a peripheral vein by a pressure injector. All patients underwent arterial and portal phase scans.

The volumetric CT dose index (CTDI vol) and dose length product (DLP) were recorded. The effective dose (ED) $(\mathrm{mSv})$ was derived from the dose-length product and age-dependent conversion coefficients.
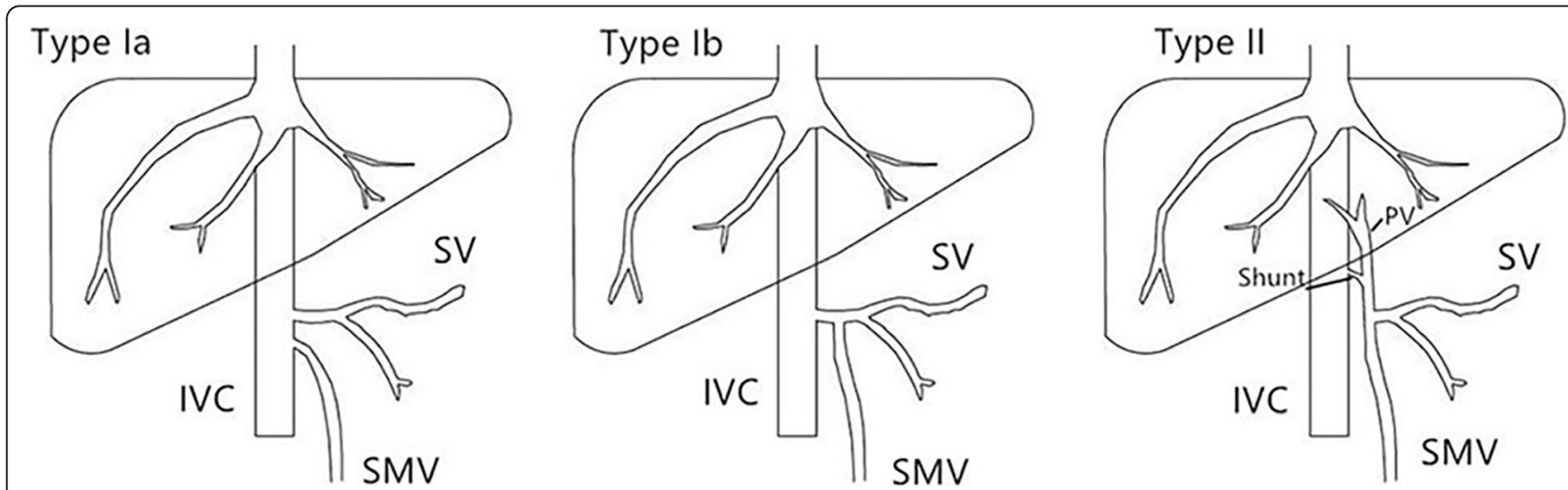

Fig. 1 Classification of Abernethy Malformation 


\section{CT image processing}

CT raw data were transferred to an Advantage Windows 4.2/4.6 workstation (General Electric Medical Systems). Maximum intensity projection (MIP) and multiplanar reformation (MPR) were the primary methods for visualization and evaluation.

\section{DSA}

DSA was performed using a digital subtraction angiography machine (Allura Xper FD10/10, PHILIPS, the Netherlands) or (INOVA 2100, General Electric Medical Systems, France) in all patients. After the puncture of arteries and veins from inguinal region, the catheter was placed at the shunt for angiography and pressure gradients were recorded. MSCT findings were compared with that of DSA.

\section{Statistical analysis}

The same two radiologists with more than 10 years experiences also confirmed CT diagnosis based on the CT findings separately. Any discrepancies were resolved by independent review. By comparing the findings of MSCT with DSA, we were able to calculate diagnostic accuracy.

\section{Results}

\section{Patient information}

Fourteen cases were admitted to our hospital (Table 1). The fourteen patients experienced a variety of clinical features, which included hematochezia (case 3), cyanosis (cases 4,9,14), fatigue (cases 5,7,8,12), hematuria (case 10 ), and pulmonary hypertension (cases $2,3,6,7,11,12,13$ ). Six patients $(6 / 14)$ were diagnosed as having congenital heart disease (ventricular septal defect (VSD), patent ductus arteriosus (PDA), atrial septal defect (ASD), polysplenia syndrome, and partial anomalous pulmonary venous connection (PAPVC)). Two (2/14) had abnormal liver function, ten (10/14) had hyperammonemia, three (3/14) had nodular liver lesions, one patient (1/14) had hepatic encephalopathy, and four (4/14) patients had pulmonary arteriovenous fistula.

\section{MSCT findings}

Using MSCT, we were able to show the location of the shunt between the portal vein and systemic circulation for all 14 cases. Among the fourteen patients, ten presented with single vessel shunt between portal vein and IVC (Fig. 2), one with shunt between the portal vein and left renal vein, one with shunt between the superior mesenteric vein and left renal vein, one with shunt between the splenic vein and right iliac vein, and one with shunt between splenic vein and the left iliac vein (Fig. 3).

The two radiologists' diagnosis was the same. Five children with Abernethy malformation type Ib and nine children with type II were identified by MSCT. Compared with DSA and surgical results, two cases of type II Abernethy malformation were misdiagnosed as type Ib Abernethy malformation in MSCT (Table 2). The accuracy rate of this method was $85.7 \%$ (12/14). Intrahepatic lesions were found in three patients using MSCT.

The mean DLP (Dose length product) for cases using the 16-row CT scanner was $371.353 \pm 176.583 \mathrm{mGy}$-cm, mean CTDI was $14.49 \pm 5.973 \mathrm{mGy}$, resulting in an estimated mean effective dose (ED) of $6.948 \pm 4.561 \mathrm{mSv}$. The DLP, CTDI and calculated ED for cases using the 64-slice high definition CT scanner were $106.100 \pm 48.312 \mathrm{mGy}$ $\mathrm{cm}, 4.50 \pm 2.155 \mathrm{mGy}$ and $2.593 \pm 1.490 \mathrm{mSv}$.

\section{DSA findings}

All patients who received DSA had their shunt identified by DSA. Hypoplastic portal veins were visualized in patients of which two were not visualized in MSCT.

\section{Surgical}

Eleven cases were treated after diagnosis. One patient with Abernethy malformation type Ib (1/3) underwent liver transplantation. Seven patients with Abernethy malformation type II (7/11) were treated by shunt occlusion, received laparoscopy, or were treated with open surgical ligation. Another three patients (3/11) with Abernethy malformation type II were treated by interventional portocaval shunt occlusion under DSA. The remaining 3 cases (two with type $\mathrm{Ib}$ and one with type II) were lost to follow-up.

Of the eleven treated patients, eight were followed up after treatment (case 2, 5, 6, 7, 9, 12, 13, 14). Their blood oxygen saturation reached normal level and their symptoms were alleviated to varying degrees compared with those before operation. Among the eight cases, five patients' serum ammonia level returned to normal (case 6, $7,9,12,13$, preoperative serum ammonia level was normal in other three patients.). DSA was reexamined in four patients within 1-3 years after treatment, which showed that the development of intrahepatic portal vein was better than that before treatment (case 5, 6, 7, 14). Pulmonary arteriovenous fistula disappeared in two patients (case 9, 14). Pulmonary hypertension still existed in three patients (case 7, 12, 13).

\section{Discussion}

Abernethy malformation, also known as congenital extrahepatic portosystemic shunt, is an extremely rare syndrome. The majority of affected patients described to date were under the age of 18 [2-4]. Type I malformations have complete portosystemic shunts that do not perfuse the liver and are predominantly found in females [5-7]. Type II malformations have a hypoplastic portal vein leading to liver perfusion. 
Table 1 Summary of findings in patients with Abernethy Malformation

\begin{tabular}{|c|c|c|c|c|}
\hline $\begin{array}{l}\text { Case } \\
\text { No. }\end{array}$ & Age $(y) / S e x$ & Clinical Features & $\begin{array}{l}\text { Fistula classification and } \\
\text { anatomy }\end{array}$ & Treatment \\
\hline 1 & $\begin{array}{l}11 \text { years/ } \\
\text { Female }\end{array}$ & VSD, Hyperammonemia, Abnormal liver function & Type Ib(PV-IVC) & Lost to follow-up \\
\hline 2 & $\begin{array}{l}6 \text { years/ } \\
\text { Female }\end{array}$ & $\begin{array}{l}\mathrm{PH} \text {, } \\
\text { Nodular liver lesions }\end{array}$ & Type Ib(PV-IVC) & Liver transplantation \\
\hline 3 & $\begin{array}{l}12 \text { years/ } \\
\text { Male }\end{array}$ & $\begin{array}{l}\text { Hematochezia, } \mathrm{PH}, \\
\text { Hyperammonemia }\end{array}$ & Type Ib(SV-iliac vein-IVC) & Lost to follow-up \\
\hline 4 & $\begin{array}{l}11 \text { years/ } \\
\text { Female }\end{array}$ & $\begin{array}{l}\text { Cyanosis, Pulmonary arteriovenous fistula, } \\
\text { Hyperammonemia }\end{array}$ & Type II(PV-IVC) & Surgical shunt occlusion \\
\hline 5 & $\begin{array}{l}9 \text { years/ } \\
\text { Male }\end{array}$ & Fatigue, PDA, Nodular liver lesions & Type II(PV-IVC) & Surgical shunt occlusion \\
\hline 6 & $\begin{array}{l}4 \text { years/ } \\
\text { Male }\end{array}$ & PH, Hyperammonemia & Type II(PV-IVC) & Surgical shunt occlusion \\
\hline 7 & $\begin{array}{l}9 \text { years/ } \\
\text { Male }\end{array}$ & $\begin{array}{l}\text { Fatigue, PH, } \\
\text { Hepatic encephalopathy, Heart insufficiency, } \\
\text { Hyperammonemia }\end{array}$ & Type II(PV-IVC) & Surgical shunt occlusion \\
\hline 8 & $\begin{array}{l}14 \text { years/ } \\
\text { Male }\end{array}$ & $\begin{array}{l}\text { Fatigue, VSD, } \\
\text { Hyperammonemia, Nodular liver lesions }\end{array}$ & Type II(PV-IVC) & Lost to follow-up \\
\hline 9 & $\begin{array}{l}5 \text { years/ } \\
\text { Male }\end{array}$ & $\begin{array}{l}\text { Cyanosis, Pulmonary arteriovenous fistula, } \\
\text { Hyperammonemia }\end{array}$ & Type II(PV-IVC) & $\begin{array}{l}\text { Interventional portocaval shunt } \\
\text { occlusion under DSA }\end{array}$ \\
\hline 10 & $\begin{array}{l}10 \text { years/ } \\
\text { Female }\end{array}$ & $\begin{array}{l}\text { Hematuria, Renal vascular malformation, } \\
\text { Hyperammonemia }\end{array}$ & Type II(SV-iliac vein-IVC) & Surgical shunt occlusion \\
\hline 11 & $\begin{array}{l}3 \text { years/ } \\
\text { Female }\end{array}$ & $\begin{array}{l}\text { ASD,PH, } \\
\text { Abnormal liver function }\end{array}$ & Type II(PV-IVC) & $\begin{array}{l}\text { Interventional portocaval shunt } \\
\text { occlusion under DSA }\end{array}$ \\
\hline 12 & $\begin{array}{l}4 \text { years/ } \\
\text { Male }\end{array}$ & $\begin{array}{l}\text { Fatigue, ASD/PAPVC, Pulmonary arteriovenous fistula, } \\
\text { Hyperammonemia, PH }\end{array}$ & Type II(PV-LRV-IVC) & Surgical shunt occlusion \\
\hline 13 & $\begin{array}{l}7 \text { years/ } \\
\text { Male }\end{array}$ & PH, Hyperammonemia & Type II(PV-IVC) & Surgical shunt occlusion \\
\hline 14 & $\begin{array}{l}1 \text { year/ } \\
\text { Female }\end{array}$ & $\begin{array}{l}\text { Cyanosis, ASD, Polysplenia syndrome, Pulmonary } \\
\text { arteriovenous fistula }\end{array}$ & Type II(SMV-LRV-IVC) & $\begin{array}{l}\text { Interventional portocaval shunt } \\
\text { occlusion under DSA }\end{array}$ \\
\hline
\end{tabular}

$P V=$ portal vein; $I V C=$ inferior vena cava; $S M V=$ Superior mesenteric vein; $L R V=$ left renal vein; $A S D=$ atrial septal defect; $V S D=$ ventricular septal defect; $P D A=$ patent ductus arteriosus; $P A P V C=$ partial anomalous pulmonary venous connection; $P H=$ pulmonary hypertension
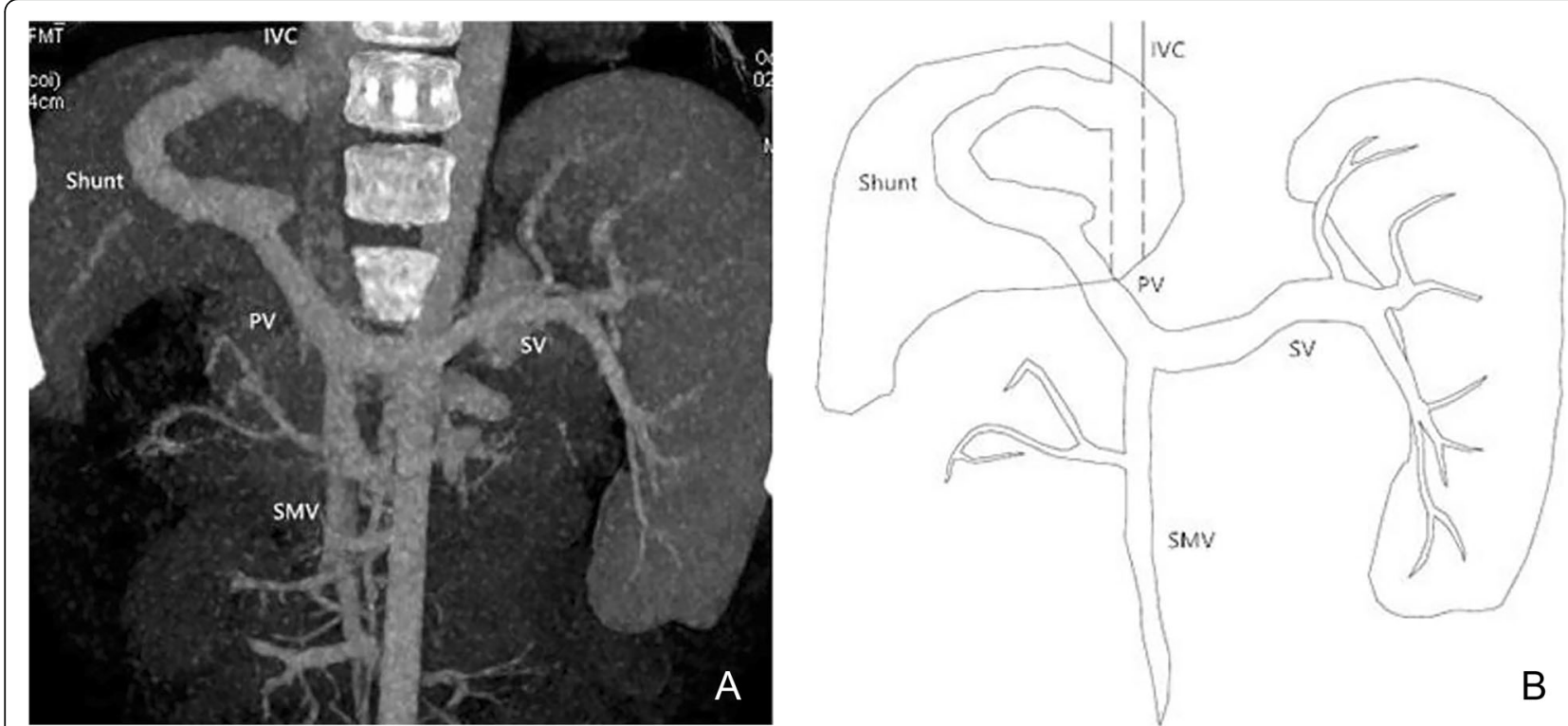

Fig. 2 Male, 7 years old, Abernethy II. Abdominal CT angiography maximum intensity projection (MIP) image (portal phase) shows the shunt of extrahepatic portosystemic between portal vein and inferior vena cava 

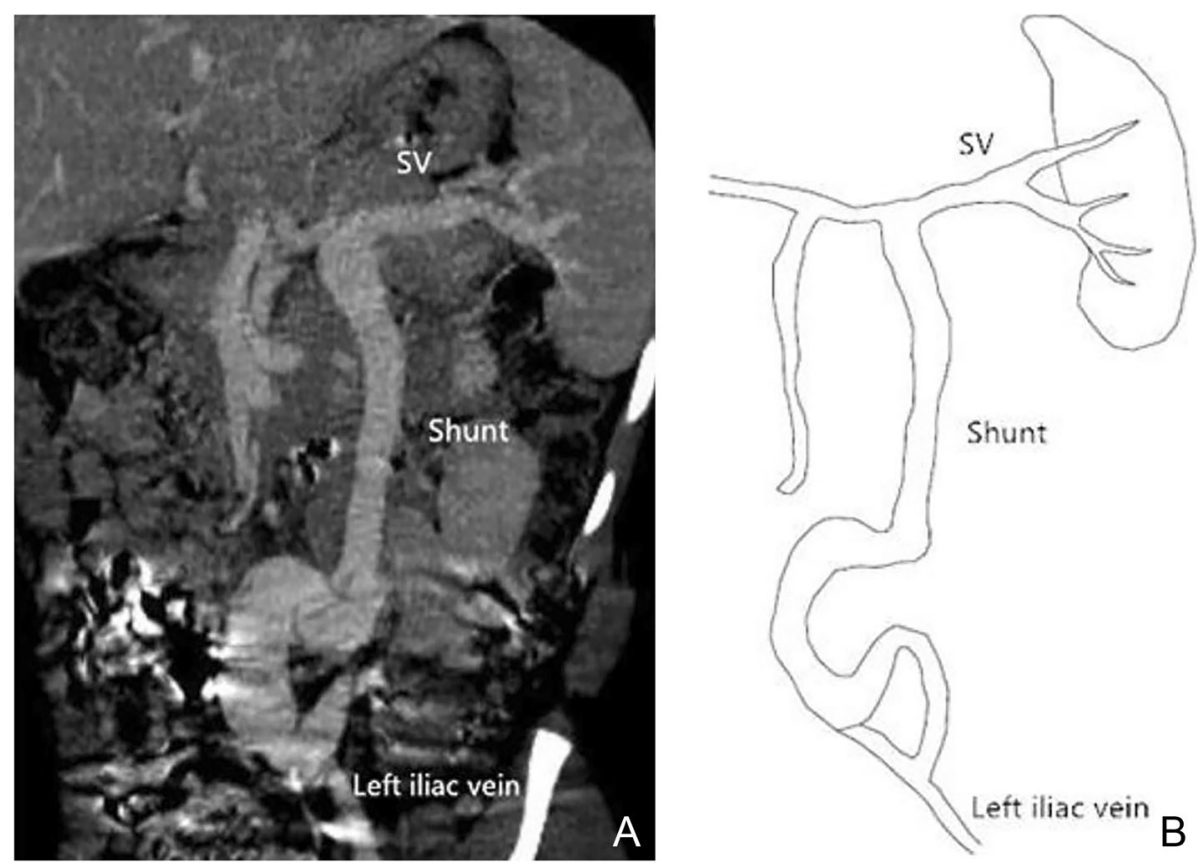

Fig. 3 Female, 10 years old, Abernethy II. Abdominal CT angiography maximum intensity projection (MIP) image (portal phase) shows the shunt of extrahepatic portosystemic between splenic vein and left iliac vein

As shown in our cases, Abernethy malformations have a wide spectrum of symptoms including hematochezia, cyanosis, fatigue, hematuria, and others. Other relevant symptoms recorded in studies include nausea, vomiting, epigastric pain, asthenia, anorexia, jaundice, and dyspnea [4]. The symptoms may be mild and non-specific, with some patients being asymptomatic $[8,9]$. Pulmonary hypertension is a frequent initial clinical manifestation of the disease and hyperammonemia is a common manifestation. In our group, 50\% (7/14) patients presented with unexplained pulmonary hypertension, and $71.4 \%$ (10/14) had hyperammonemia. Severe elevation of blood ammonia can lead to hepatic encephalopathy but only one of our 14 cases had this manifestation.

Abernethy malformation is frequently associated with cardiovascular abnormalities, including atrial septal defect (ASD), patent foramen ovale (PFO), ventricular septal defect (VSD), patent ductus arteriosus (PDA), tetralogy of Fallot (TOF) and dextrocardia [1, 5, 6, 10, $11]$. In our 14 cases, $42.9 \%(6 / 14)$ cases had a history of

Table 2 Accuracy of Classification of Abernethy malformation in MSCT Compared with DSA

\begin{tabular}{|c|c|c|}
\hline \multirow[t]{2}{*}{ DSA } & MSCT & \multirow{2}{*}{$\begin{array}{l}\text { Accuracy } \\
(\%)\end{array}$} \\
\hline & la lb || & \\
\hline $\mathrm{la}(n=0)$ & 000 & / \\
\hline $\mathrm{Ib}(n=3)$ & 030 & 100.0 \\
\hline$\|(n=11)$ & 029 & 81.8 \\
\hline
\end{tabular}

congenital heart disease, and included ASD, VSD, PDA, PAPVC, and polysplenia syndrome (one patient with type I and five patients with type II). Some studies have indicated that type I Abernethy malformation occurs more frequently in girls and is associated with other congenital anomalies, while type II Abernethy shunts are rarely seen with these malformations $[9,12,13]$. Two of three cases of type I Abernethy malformation were female patients. However, in our eleven cases of type II, five cases had congenital heart disease. Nodular liver lesions were observed in almost half of the reported cases, and attributed to the absence of portal blood flow and compensatory increased hepatic arterial blood flow. The most frequently observed lesion is focal nodular hyperplasia, while others include nodular regenerated hyperplasia, hepatoblastoma, hepatic adenoma, hepatocellular carcinoma, and cirrhosis [4]. Only $21.4 \%$ of our cases (3/14) showed nodular liver lesions but were not confirmed by pathology.

When a portosystemic shunt carries an increased risk of hepatic encephalopathy or is associated with the development of liver tumors, it requires treatment [14]. Early diagnosis is important. Many image modalities can be used for diagnosing Abernethy malformation, including ultrasound, CT, DSA, and MRI.

Ultrasound is a non-invasive method of examination. Eight of the fourteen cases underwent US in our study, and all eight cases were able to confirm Abernethy malformation by showing the exact position of the shunt. 
However, compared with MSCT, US did not clearly show the development of the intrahepatic portal vein. Hypoplastic portal veins were found in only two cases using US. It would appear that confirmation of the type of Abernethy malformation by US is less efficient compared with MSCT.

MSCT is a non-invasive imaging technique with high spatial resolution and the ability to rapidly test for the diagnosis of Abernethy malformation. We have a lowdose CT protocol $(100-120 \mathrm{kVp}, 50 \mathrm{~mA})$ for children since the procedure involves ionizing radiation. In our 14 cases, MSCT was able to show the exact location of the portocaval shunt (Fig. 4) in all cases. Through postprocessing technology (MPR, MIP, VR), CT can visually display the location of shunt and its relationship with surrounding tissues. Among these imaging examinations, MSCT is a relatively efficient method. The major advantages of CTA are rapid examination and easy availability, with a very short scanning time [15]. First of all, it is a non-invasive and rapid method of imaging examination. Secondly, CT can accurately display the relationship between the location of shunt and the surrounding tissues. MSCT can give accurate classification of Abernethy malformation (Type II) especially in cases where the intrahepatic portal vein can be accurately demonstrated. Therefore, MSCT can accurately follow up these patients without using DSA each time.

Radiation dose is the main concern in imaging pediatric patients. The organ doses delivered from a traditional CT examination result in a potentially increased risk of radiation-induced carcinogenesis, particularly for children [16]. Of our 14 cases, three cases used 64-slice high definition CT scanner. The DLP, CTDI and calculated ED for cases using the 64-slice high definition CT scanner were significantly lower than those using 16-row CT scanner. However, advances in CT technology can reduce the radiation dose to patients on the premise of ensuring image quality. GE Healthcare developed a novel iterative reconstruction technique, ASiR-V, which uses almost full iterative reconstruction system with the potential for significant radiation dose reduction and superior image quality than conventional $\mathrm{ASiR}$ and a shorter imaging processing time than the model-based iterative reconstruction [17]. The use of wide detector technology and the acceleration of scanning speed also help to reduce the radiation dose of children's CT examination [18].

The conventional original non-contrast MRA techniques such as time of fight and phase contrast MR angiography produce static images with prolonged acquisition time and cannot detect small vessels. Several non-contrast and contrast enhanced MR angiography (MRA) techniques have been developed [19]. New developments of non-contrast MRA include cardiac-gated 3D fast-spin-echo, arterial spin labeling, and balanced steady-state free-precession. These techniques have better image quality and shorter examination time, but they may be associated with flow artifacts. Due to problems such as sedation, lower spatial resolution, and long examination time, none of our cases underwent MRI examination. For young children, longer examination time means deeper levels of sedation. The number of procedures requiring anesthesia and or sedation in these children is growing and the cumulative effect of these repeated exposures on the developing brain is unknown [20]. The possible side effects of sedatives on children, especially newborns, cannot be ignored. Recent several vivo studies have shown that early use of anesthetics and sedatives can lead to permanent structural and functional changes of central nervous system (CNS) [21]. Compared with MRI, CT has a very fast scanning speed. Wide-detector CT makes CT scanning with lighter to

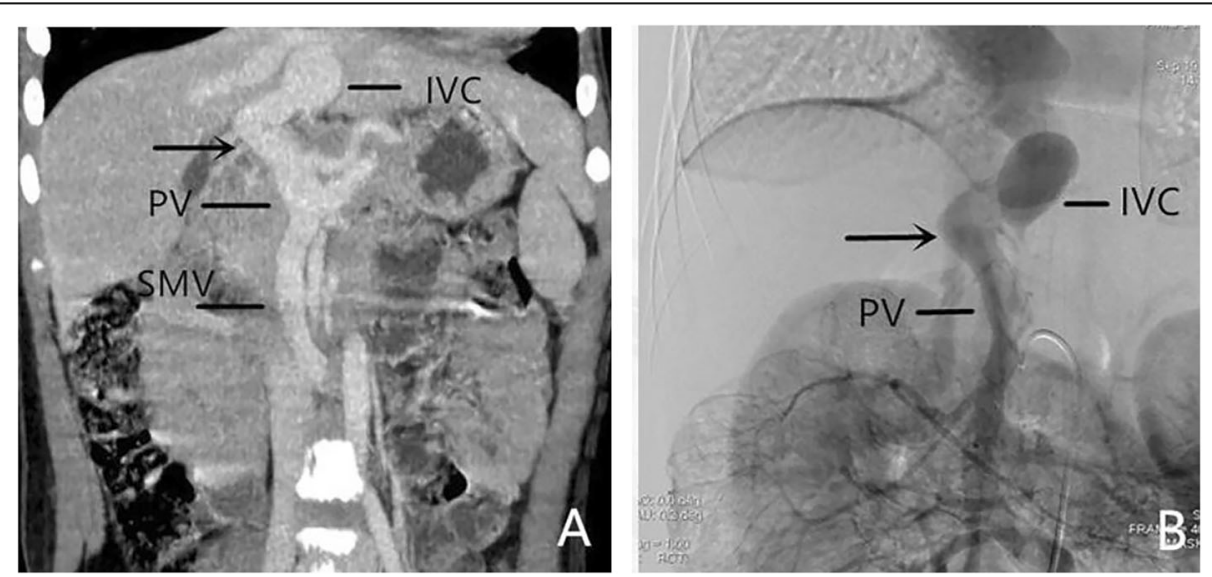

Fig. 4 Female, 11 years old, Abernethy Ib. a: Abdominal $C T$ angiography maximum intensity projection (MIP) image (portal phase) shows the presence of extrahepatic portosystemic shunt (arrow) with absence of intrahepatic portal veins. b: DSA image confirmed the MSCT result 


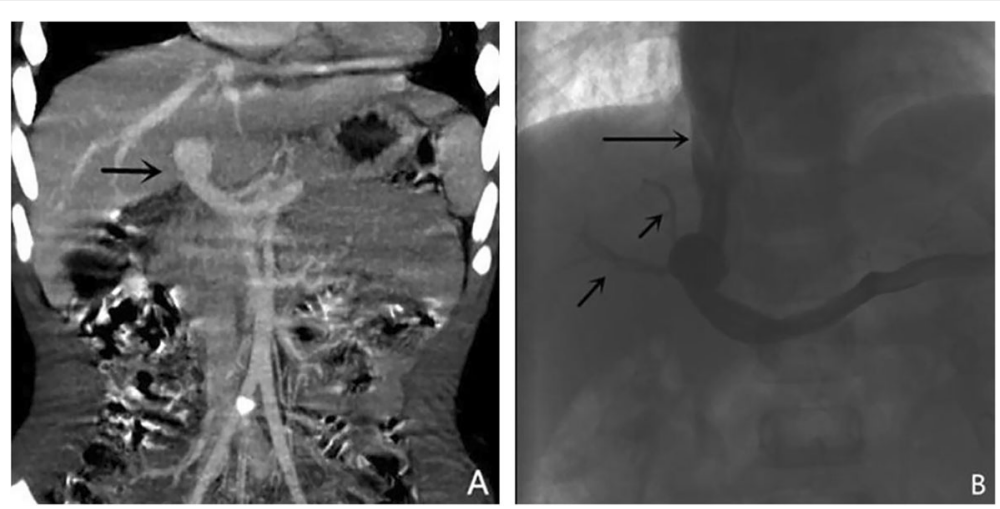

Fig. 5 Male, 3 years old, Abernethy II. a: Abdominal CT angiography maximum intensity projection (MIP) image (portal phase) shows the presence of extrahepatic portosystemic shunt (arrow) with absence of intrahepatic portal veins and diagnoses Abernethy Ib;b: DSA image shows the shunt (long arrow) and the tiny intrahepatic portal veins (short arrow)

no sedation possible due to the advancement of CT technology [20]. It is believed that with the advancement of technology, the acceleration of scanning speed and the optimization of image quality, MRA will play an increasingly important role in the diagnosis of small vessel diseases in children.

However, some patients with Abernethy type II have extremely hypoplastic portal veins distal to the shunt that are sometimes difficult to visualize with CT angiography scan. In these patients, DSA is still essential for studying the anatomy of the shunt. Among our fourteen cases, two cases of type II Abernethy malformation were misdiagnosed as type Ib Abernethy malformation using MSCT. As shown in Fig. 5, MSCT was not able to show the tiny intrahepatic portal veins, which could be seen in the DSA image. In the cases of Abernethy malformation, due to the presence of portosystemic shunt, the pressure of intrahepatic portal vein is higher than that of systemic vein. Contrast agents are more likely to enter the systemic vein through communicating branches. During DSA examination, after balloon occlusion in the shunt, the contrast agents failed to enter the systemic vein, which increased the pressure of the small portal vein branches in the liver [12]. Therefore, DSA images can show extremely hypoplastic portal vein branches in the liver which not able to be shown in CT images.

DSA remains the gold standard for the diagnosis of the disease, although it is an invasive imaging examination. However, it is especially useful for cases where the development of intrahepatic portal vein cannot be accurately demonstrated in MSCT, and consequently DSA is a necessary diagnostic regimen. Another important point is that some cases of Abernethy Malformation can be treated using DSA.

The treatment of Abernethy malformation is dictated by the classification. Type I malformations are definitively treated by liver transplantation due to complete absence of intrahepatic portal veins [22]. Type II malformations can be treated with either surgical ligation or endovascular shunt occlusion. When the shunt is not amenable to surgical closure, the only alternative is liver transplantation [13].

\section{Limitation}

There are some limitations in our study. First of all, our research was a retrospective small sample-size study although given the rarity of the condition, we are restricted by the rare incidence of this condition. Secondly, the imaging examination and description of some of the cases were incomplete. Thirdly, some cases were lost to follow-up. In future, we will expand our sample size when performing a future study.

\section{Conclusion}

In summary, it is essential to confirm the type of Abernethy malformation in the affected individual since there are different treatments for the two types. MSCT can accurately diagnose type II Abernethy malformation while showing the exact location of the portocaval shunt. Sometimes, it is hard to confirm the diagnosis between Abernethy type Ib and II because of the failure to visualize the extremely hypoplastic portal veins distal to the shunt with CT angiography. DSA still remains the gold standard in diagnosing Abernethy malformation.

\section{Abbreviations}

ASD: Atrial septal defect; DSA: Digital subtraction angiography; IVC: Inferior vena cava; MIP: Maximum intensity projection; MPR: Multiplanar reformation; MSCT: Multi-slice computed tomography; PAPVC: Partial anomalous pulmonary venous connection; PDA: Patent ductus arteriosus; PFO: Patent foramen ovale; TOF: Tetralogy of Fallot; VSD: Ventricular septal defect

\section{Acknowledgements}

Not applicable.

Availability of data and material Not applicable. 


\section{Authors' contributions}

CG, QW and Y-MZ were major contributors in writing the manuscript and reviewing literatures. L-WH was in charge of case collection and data statistics. X-HG was in charge of DSA image diagnosis. HS was in charge of $\mathrm{CT}$ image diagnosis. WW was in charge of ultrasound examination and diagnosis. J-FC was in charge of DSA examination. H-SQ was in charge of CT examination.

\section{Funding}

Not applicable.

\section{Ethics approval and consent to participate}

Not applicable.

\section{Consent for publication}

Not applicable.

\section{Competing interests}

The authors declare that they have no competing interests.

Received: 3 July 2019 Accepted: 28 November 2019

Published online: 17 December 2019

\section{References}

1. Morgan G, Superina R. Congenital absence of the portal vein: two cases and a proposed classification system for portasystemic vascular anomalies. J Pediatr Surg. 1994;29:1239-41.

2. Mistinova J, Valacsai F, Varga I. Congenital absence of the portal vein: case report and a review of literature. Clin Anat. 2010;23:750-8.

3. Witters P, Maleux G, George C. Congenital veno-venous malformations of the liver: widely variable clinical presentations. J Gastroenterol Hepatol Aug. 2008;23(8 Pt 2):e390-4

4. Hao Y, Hong X, Zhao X. Congenital absence of the portal vein associated with focal nodular hyperplasia of the liver and congenital heart disease Abernethy malformation: a case report and literature review. Oncol Lett. 2015:9(2):695-700.

5. Howard ER, Davenport M. Congenital extrahepatic portocaval shunts: the Abernethy malformation. J Pediatr Surg. 1997;32:494-7.

6. Murray CP, Yoo SJ, Babyn PS. Congenital extrahepatic portosystemic shunts. Pediatr Radiol. 2003;33:614-20.

7. Grazioli L, Alberti D, Olivetti L, et al. Congenital absence of portal vein with nodular regenerative hyperplasia of the liver. Eur Radiol. 2000;10:820-5.

8. Bas S, Guran T, Atay Z, Haliloglu B, Abalı S, Turan S, Bereket A. Premature pubarche, hyperinsulinemia and hypothyroxinemia: novel manifestations of congenital portosystemic shunts Abernethy malformation in children. Horm Res Paediatr. 2015;83(4):282-7.

9. Kwapisz L, Wells MM, AlJudaibi B. Abernethy malformation: congenital absence of the portal vein. Can J Gastroenterol Hepatol. 2014;28(11):587-8.

10. Kumar A, Kumar J, Aggarwal R, Srivastava S. Abernethy malformation with portal vein aneurysm. Diagn Interv Radiol. 2008;14:143-6.

11. Hu GH, Shen LG, Yang J, Mei JH, Zhu YF. Insight into congenital absence of the portal vein: is it rare? World J Gastroenterol. 2008;14:5969-79.

12. Lautz TB, Tantemsapya N, Rowell E, Superina RA. Management and classification of type II congenital portosystemic shunts. J Pediatr Surg. 2011; 46(2):308-14.

13. Passalacqua M, Lie KT, Yarmohammadi H. Congenital extrahepatic portosystemic shunt (Abernethy malformation) treated endovascularly with vascular plug shunt closure. Pediatr Surg Int. 2012;28(1):79-83.

14. Stringer MD. The clinical anatomy of congenital portosystemic venous shunts. Clin Anat. 2008:21:147-57.

15. Abdel Razek AA, Denewer AT, Hegazy MA, Hafez MT. Role of computed tomography angiography in the diagnosis of vascular stenosis in head and neck microvascular free flap reconstruction. Int J Oral Maxillofac Surg. 2014; 43(7):811-5

16. Brenner D, Elliston $\mathrm{C}$, Hall $\mathrm{E}$, Berdon W. Estimated risks of radiation-induced fatal cancer from pediatric CT. AJR Am J Roentgenol. 2001;176(2):289-96.

17. Elmokadem AH, Ibrahim EA, Gouda WA, Razek AA. Whole-Body Computed Tomography Using Low-Dose Biphasic Injection Protocol With Adaptive Statistical Iterative Reconstruction V: Assessment of Dose Reduction and Image Quality in Trauma Patients. J Comput Assist Tomogr. 2019;43(6):870-876.
18. Zhu Y, Li Z, Ma J, et al. Imaging the infant chest without sedation: feasibility of using single axial rotation with 16-cm wide-detector CT. Radiology. 2018; 286(1):279-285.

19. Razek AA, Gaballa G, Megahed AS, Elmogy E. Time resolved imaging of contrast kinetics (TRICKS) MR angiography of arteriovenous malformations of head and neck. Eur J Radiol. 2013;82(11):1885-91.

20. Char D, Ramamoorthy C, Wise-Faberowski L. Cognitive dysfunction in children with heart disease: the role of anesthesia and sedation. Congenit Heart Dis. 2016:11:221-9.

21. Barton K, Nickerson JP, Higgins T, et al. Pediatric anesthesia and neurotoxicity: what the radiologist needs to know. Pediatr Radiol. 2018; 48(1):1-6

22. Watanabe A. Portal-systemic encephalopathy in non-cirrhotic patients: classification of clinical types, diagnosis and treatment. J Gastroenterol Hepatol. 2000;15(9):969-79.

\section{Publisher's Note}

Springer Nature remains neutral with regard to jurisdictional claims in published maps and institutional affiliations.
Ready to submit your research? Choose BMC and benefit from:

- fast, convenient online submission

- thorough peer review by experienced researchers in your field

- rapid publication on acceptance

- support for research data, including large and complex data types

- gold Open Access which fosters wider collaboration and increased citations

- maximum visibility for your research: over $100 \mathrm{M}$ website views per year

At $\mathrm{BMC}$, research is always in progress.

Learn more biomedcentral.com/submissions 